\title{
Characterization of Mediterranean hail-bearing storms using an operational polarimetric $\mathrm{X}$-band radar
}

\author{
G. Vulpiani ${ }^{1}$, L. Baldini ${ }^{2}$, and N. Roberto ${ }^{2}$ \\ ${ }^{1}$ Department of Civil Protection, Rome, Italy \\ ${ }^{2}$ Institute of Atmospheric Sciences and Climate - National Research Council, Rome, Italy \\ Correspondence to: G. Vulpiani (gianfranco.vulpiani@protezionecivile.it)
}

Received: 12 June 2015 - Published in Atmos. Meas. Tech. Discuss.: 14 July 2015

Revised: 23 October 2015 - Accepted: 26 October 2015 - Published: 6 November 2015

\begin{abstract}
This work documents the effective use of X-band radar observations for monitoring severe storms in an operational framework. Two severe hail-bearing Mediterranean storms that occurred in 2013 in southern Italy, flooding two important Sicilian cities, are described in terms of their polarimetric radar signatures and retrieved rainfall fields. The $\mathrm{X}$-band dual-polarization radar operating inside the Catania airport (Sicily, Italy), managed by the Italian Department of Civil Protection, is considered here. A suitable processing is applied to X-band radar measurements. The crucial procedural step relies on the differential phase processing, being preparatory for attenuation correction and rainfall estimation. It is based on an iterative approach that uses a very short-length $(1 \mathrm{~km})$ moving window, allowing proper capture of the observed high radial gradients of the differential phase. The parameterization of the attenuation correction algorithm, which uses the reconstructed differential phase shift, is derived from electromagnetic simulations based on 3 years of drop size distribution (DSD) observations collected in Rome (Italy). A fuzzy logic hydrometeor classification algorithm was also adopted to support the analysis of the storm characteristics. The precipitation field amounts were reconstructed using a combined polarimetric rainfall algorithm based on reflectivity and specific differential phase. The first storm was observed on 21 February when a winter convective system that originated in the Tyrrhenian Sea, marginally hit the central-eastern coastline of Sicily, causing a flash flood in Catania. Due to an optimal location (the system is located a few kilometers from the city center), it was possible to retrieve the storm characteristics fairly well, including the amount of rainfall field at the ground. Extemporaneous signal extinction, caused by close-range hail core causing sig-
\end{abstract}

nificant differential phase shift in a very short-range path, is documented. The second storm, on 21 August 2013, was a summer mesoscale convective system that originated from a Mediterranean low pressure system lasting a few hours that eventually flooded the city of Syracuse. The undergoing physical process, including the storm dynamics, is inferred by analyzing the vertical sections of the polarimetric radar measurements. The high registered amount of precipitation was fairly well reconstructed, although with a trend toward underestimation at increasing distances. Several episodes of signal extinction were clearly manifested during the mature stage of the observed supercells.

\section{Introduction}

Dual-polarization technology has greatly improved the quality of radar precipitation measurements and reduced the gap between the qualitative and quantitative use of radar observations. Several operational S- and C-band radar networks have been (or will soon be) upgraded to adopt dual-polarization technology. In the past decade, many studies have been undertaken to explore the benefit of polarimetry for quantitative precipitation estimation (QPE) using X-band radars (Anagnostou et al., 2004; Matrosov et al., 2005; Wang and Chandrasekar, 2010; Anagnostou et al., 2010; Matrosov et al., 2013), which are de facto very appealing systems due to their compact size, transportability and, generally, affordable cost. In the presence of hail or melting hail, QPE algorithms based on differential phase shift are a convenient means of estimating the fraction of liquid-phase precipitation (Matrosov et al., 2013; Ryzhkov et al., 2013). Attenuation remains the major 


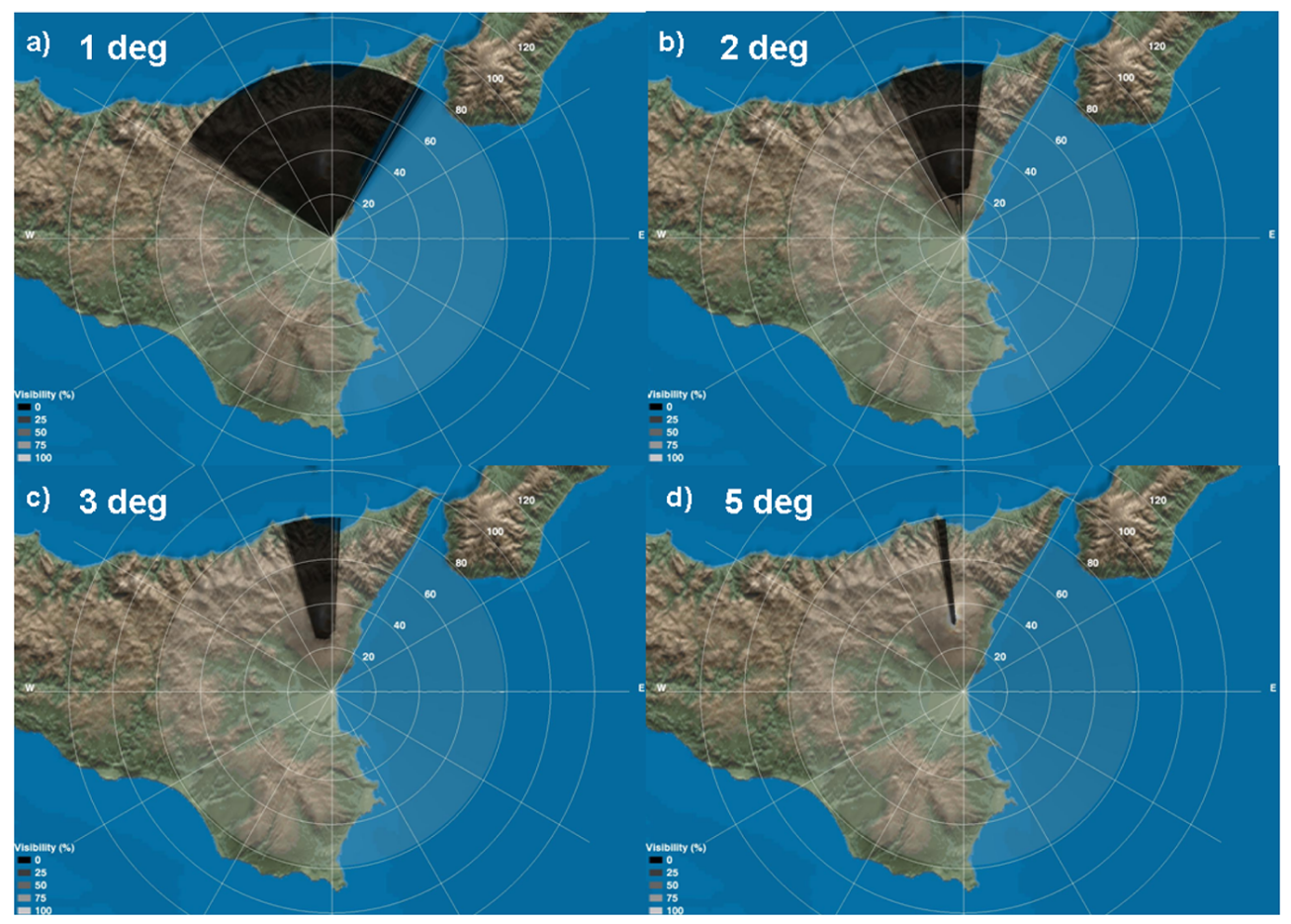

Figure 1. Visibility maps for the considered radar system as retrieved using a 250 m digital terrain model (DTM) at $1,2,3$ and $5^{\circ}$ of antenna elevation.

impairment for the operational use of X-band systems, despite the availability of robust correction methods and rainfall algorithms based on a specific differential phase that is immune to attenuation. In the presence of heavy rain and hail mixtures, partial attenuation can be further enhanced, leading to signal extinction. Heavy rain above the radar can wet the radome, adding further attenuation (see Bechini et al., 2010 and Schneebeli et al., 2012 for measurements collected by the same type of radar used in this paper). Moreover, some applications, such as the discrimination between rain and hail radar echoes, require the use of attenuation-corrected reflectivity and differential reflectivity. Furthermore, analyzing the internal structure of hail-bearing convective cells to forecast their degree of severity and evolution in time, differential phase measurements are not sufficient. Discrimination between rain and hail using radar returns is a long-standing objective of radar meteorology with impacts on nowcasting, rainfall estimation assessment, microphysical investigation, aviation, and agricultural applications. Use of weather radar for hail detection began in the 1950s with single-polarization techniques for analyzing echo intensity, spatial structure, and time evolution (Cook, 1958; Douglas and Hitschfeld, 1958). Mason (1971) suggested a $55 \mathrm{dBZ}$ reflectivity threshold as an indicator of the presence of hail in S-band radars. A refinement of the relationship between the $45 \mathrm{dBZ}$ level above the freezing layer and the occurrence of hail at the ground (Waldvogel et al., 1979) has been used by the Weather Surveillance Radar-1988 Doppler (WSR-88D) single-polarization systems. Dual-wavelength methodologies, making use of the ratio of reflectivities measured at S- and X-bands, were also proposed (Atlas and Ludlam, 1961; Eccles and Atlas, 1973). However, with the development of radar dual-polarization techniques, (Seliga and Bringi, 1976) the differential reflectivity $Z_{\mathrm{DR}}$, when used in combination with $Z_{\mathrm{H}}$ and/or other measurements, became the key radar observable used for hail detection (Seliga et al., 1982; Aydin et al., 1984, 1986; Bringi et al., 1984). The common underlying hypothesis of dualpolarization methods is the isotropic radar appearance of hail even if it is oblate; tumbling and gyrating motions confer a spherical-like behavior to hail (Knight and Knight, 1970) that brings the corresponding $Z_{\mathrm{DR}}$ signature near zero. Based on disdrometer observations, Aydin et al. (1986) suggested identifying hail by measuring the departure of the observed reflectivity factor and differential reflectivity from an empirically derived hail-rain boundary. Later, Zrnić et al. (1993) assumed that large hail, independently from the initial orientation (either oblate or prolate hailstones), tends to fall vertically, producing negative values of $Z_{\mathrm{DR}}$. However, observations of hailstones with the major axis in the horizontal are also documented in the literature (Smyth et al., 1999). According to the model proposed by Rasmussen and Heymsfield (1987), the water coat surrounding melting hail tends to stabilize the major axis in the horizontal direction, as was proved by Tabary et al. (2009) using C-band radar observations. Consequently, the fall mode, determined by the liquid water content (LWC) and updraft speed, is a crucial factor af- 
fecting the interpretation of polarimetric radar signatures and the development of hail detection algorithms. Heinselman and Ryzhkov (2006), using radar measurements at S-band, confirmed the higher performance of dual-polarization hail detection algorithms with respect to methodologies employing radar reflectivity only for the diagnosis of hail. Among the characteristics of hail-bearing precipitation cells that can be used by forecasters to infer the severity and future evolution of a storm, the most commonly known being referred to as " $Z_{\mathrm{DR}}$ column", is the appearance of positive differential reflectivity above the $0^{\circ}$ isothermal, from which information related to location and strength of updraft can be inferred (Illingworth et al., 1987; Kumjian et al., 2014 and references therein). However, such studies have shown that not only $Z_{\mathrm{DR}}$, but other dual-polarization variables should be used to correctly interpret behavior of convective cells. At attenuating frequencies and particularly at X-band, identification of hail and investigation of hail-bearing cells is more difficult. In particular, differential attenuation might have detrimental effects on any methodology involving differential reflectivity since effects of attenuation, or even effects of wrong attenuation correction, can mask intrinsic polarimetric signatures. The present work describes two very intense convective storms observed in the Mediterranean area with a mobile $\mathrm{X}$-band radar located in a flooding-prone area. The Italian peninsula is prone to intense, short-lasting events that, due to its complex orography, often impact small but densely populated catchments with short hydrological response time. The use of radar observations could be crucial for early warning purposes in such climatological and environmental frameworks. However, in complex terrain conditions, C-band radar systems might be severely affected by beam blocking. Mobile (or fixed) X-band radar observations might complement them, although attenuation can be detrimental. The quantitative use of such systems to monitor severe events in a complex environmental scenario, complementing C-band radar measurements, is tested in this work. Further, as shown in the following sections, some characteristics of the storms described here are explained by looking at the perturbation of the polarimetric radar signatures (e.g., enhanced attenuation, prominent depression of the co-polar correlation coefficient). Due to the recent success of dual-polarization X-band systems, case studies related to heavy precipitation involving hail or hail mixed with rain have been reported in the literature (Matrosov et al., 2013; Figueras i Ventura et al., 2013; Snyder et al., 2010). Notwithstanding, the basic ingredients for identifying graupel and hail formation within a convective cell can be obtained by the comparative analysis of the polarimetric radar observations. A fuzzy logic hydrometeor classification scheme is used in this paper as additional support for the analysis. The manuscript is organized as follows: Sect. 2 describes the operational contest and the data processing methodology. The precipitation events described above are analyzed in depth in Sect. 3.

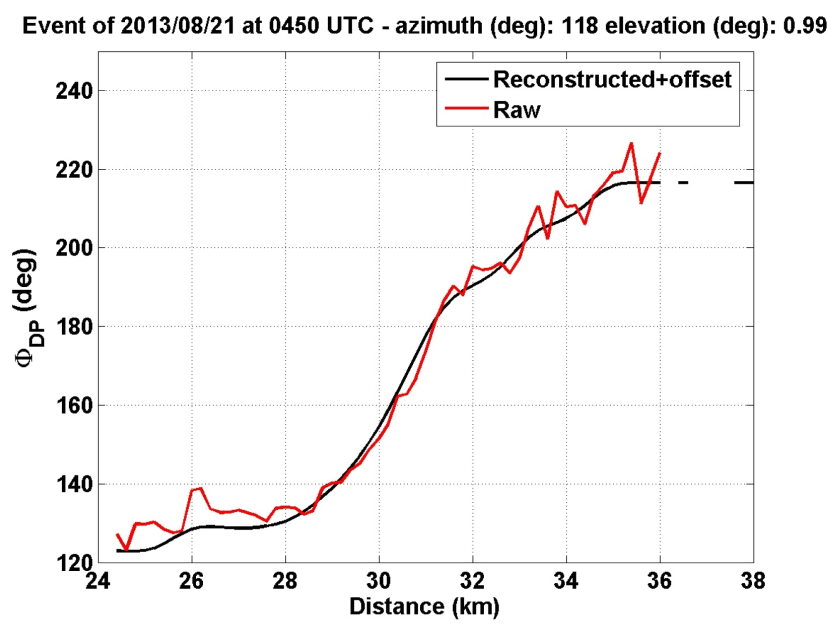

Figure 2. Examples of observed and filtered $\Phi_{\text {DP }}$ range profiles observed on 21 August 2013 at 04:50 UTC. The estimated offset has been added to the filtered $\Phi_{\mathrm{DP}}$ to simply the intercomparison.

\section{Radar and data processing systems}

\subsection{Operational scenario}

The Selex-Gematronik 50 DX polarimetric system with a $3 \mathrm{~dB}$ beam width of $1.3^{\circ}$ and $50 \mathrm{~kW}$ of transmit peak power was considered in this work. It was deployed at the airport of Catania (Sicily) at the end of 2010 and is currently integrated as a gap filler within the national weather radar network, either for weather or volcanic ash cloud monitoring (Marzano et al., 2013). The operational volume observation strategy, repeated every $10 \mathrm{~min}$, includes $12 \mathrm{PPI}$ sweeps, with antenna elevation angle ranging from 1 to $21.6^{\circ}$, and a further one at vertical-incidence used for $Z_{\mathrm{DR}}$ calibration and for a detailed characterization of the column above the radar. The adopted PRF is $1875 \mathrm{~Hz}$, which corresponds to a maximum unambiguous range of $80 \mathrm{~km}$, while the range resolution is $200 \mathrm{~m}$. The location of the Etna volcano, whose peak (about $3.2 \mathrm{~km}$ a.s.1.) is about $30 \mathrm{~km}$ north of the radar, means that a wide azimuth sector (about $90^{\circ}$ ) is shielded at low elevation scans, as depicted in Fig. 1. At $3^{\circ}$, the shielded sector shrinks to about $20^{\circ}$ of width, becoming almost negligible at $5^{\circ}$.

\subsection{Processing methodology}

The main steps of the applied processing chain, i.e., low signal ratio (SNR) compensation of $\rho_{\mathrm{HV}}$, differential phase processing, attenuation correction and rainfall estimation, are summarized briefly. Further details can be found in Vulpiani et al. (2012).

a. Noise compensation of $\rho_{\mathrm{HV}}$. Based on the standard definition for the estimator of the correlation coefficient (Bringi and Chandrasekar, 2001, see Eq. 6.110a), $\rho_{\mathrm{HV}}$ 


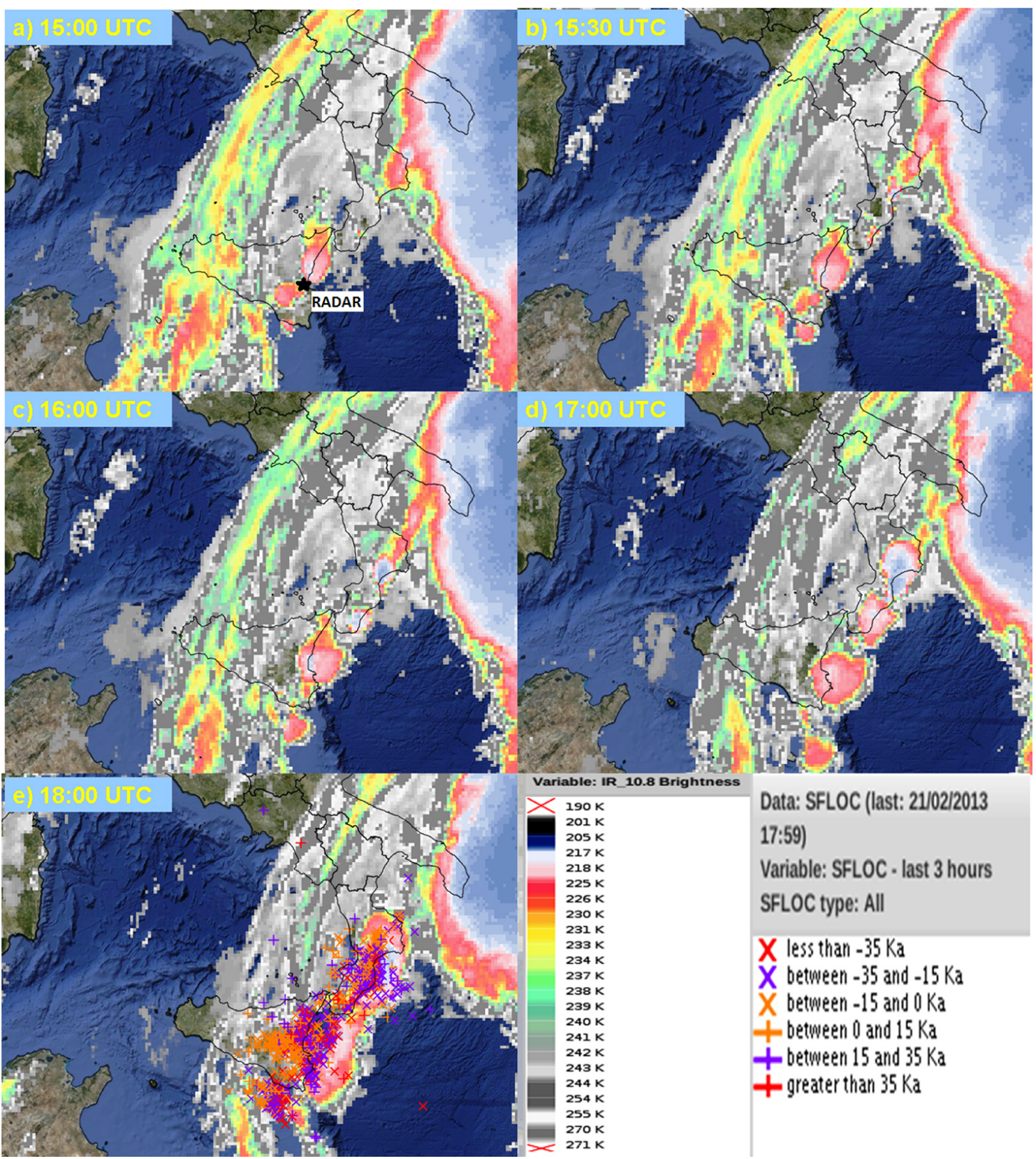

Figure 3. Brightness temperature at $10.8 \mu \mathrm{m}$ as retrieved on 21 February 2013 by the Spinning Enhanced Visible and Infrared Imager (SEVIRI) instrument on board the Meteosat Second Generation (MTG) geostationary satellite. Panel (a) shows the approximate position of the radar site, whereas panel (e) shows the lightning observations recorded between 15:00 and 18:00 UTC. As specified by the legend shown in the lower right panel, the cross mark $(+)$ and $\mathrm{X}$-mark $(\mathrm{X})$ refer to positive and negative charges, respectively.

is operationally corrected for noise every $10 \mathrm{~min}$ at radar signal processor (RSP) level through the SelexGematronik GDRX ${ }^{\circledR}$ utility called "Zero check":

$$
\rho_{\mathrm{HV}}=\frac{\left|R_{0}^{\mathrm{HV}}\right|}{\sqrt{\left|R_{0}^{\mathrm{H}}-P_{\mathrm{N}}^{\mathrm{H}}\right|\left|R_{0}^{\mathrm{V}}-P_{\mathrm{N}}^{\mathrm{V}}\right|}},
$$

where $R_{0}^{\mathrm{HV}}$ is the cross correlation between horizontal and vertical channels at lag $0, R_{0}^{\mathrm{H}}\left(R_{0}^{\mathrm{V}}\right)$ and $P_{\mathrm{N}}^{\mathrm{H}}$
$\left(P_{\mathrm{N}}^{\mathrm{V}}\right)$ are, respectively, the clutter-corrected power and the noise power from the horizontal (vertical) channel. This utility, currently scheduled between two consecutive volumetric scans, measures noise power for both horizontal and vertical channels at high antenna elevation $\left(60^{\circ}\right)$ and far ranges to avoid scattering from atmospheric targets. 

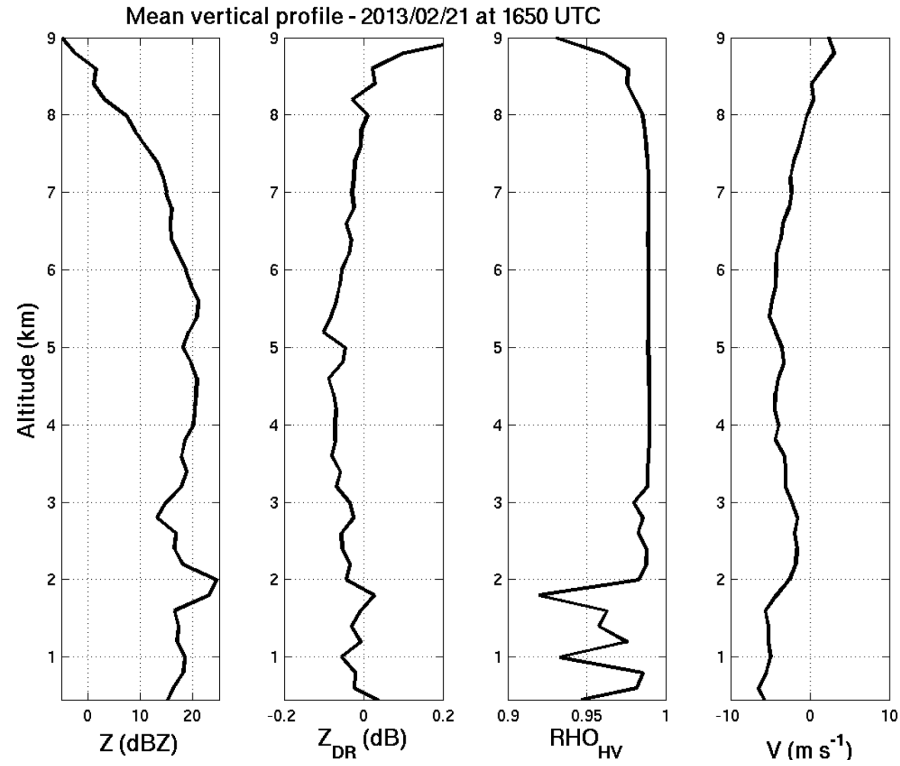

Figure 4. Mean vertical profiles of reflectivity, differential reflectivity, correlation coefficient, and Doppler velocity observed on 21 February 2013 at 16:50 UTC.

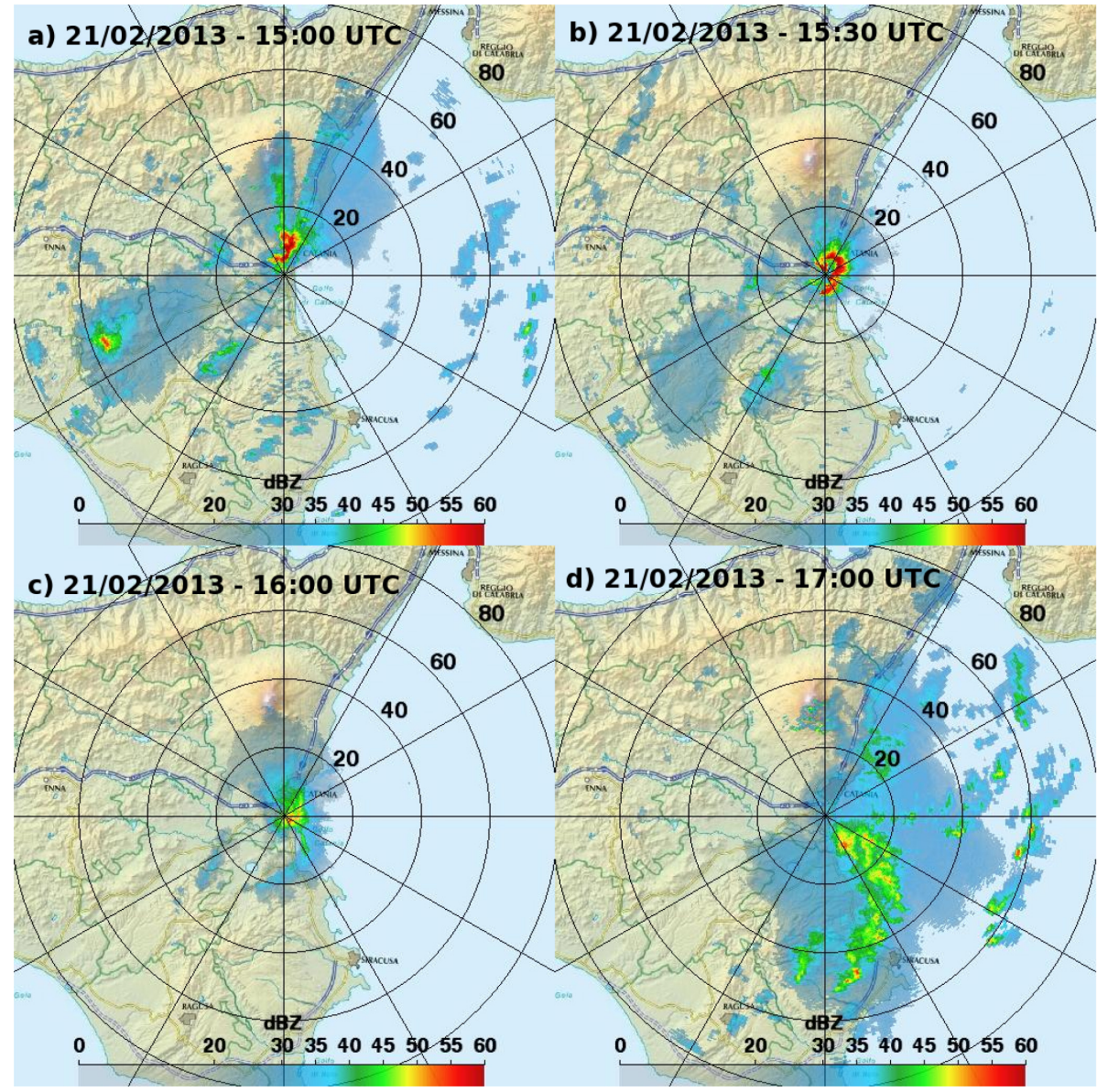

Figure 5. Vertical maximum intensity maps as retrieved on 21 February 2013 at 15:00, 15:30, 16:00 and 17:00 UTC. 

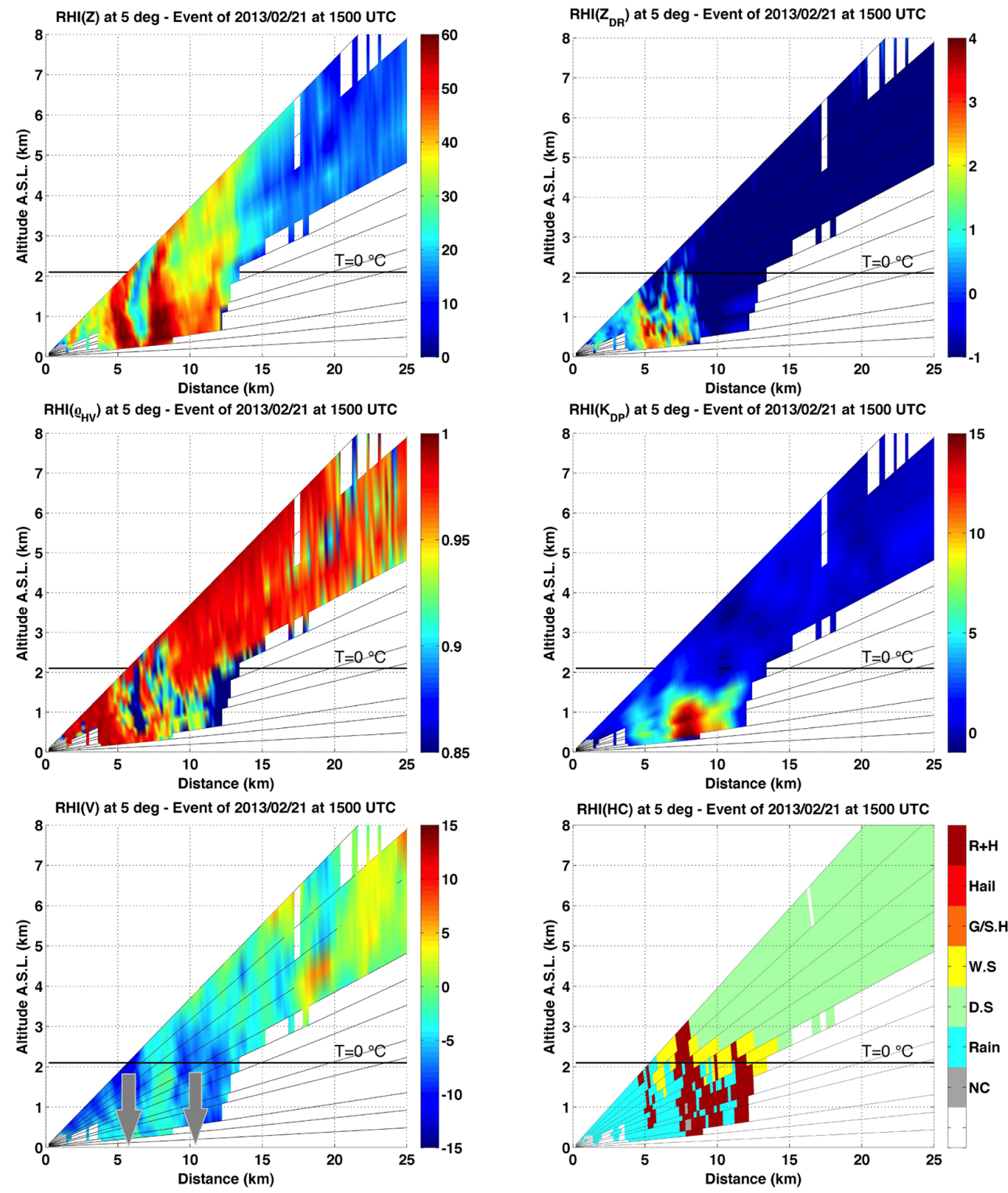

Figure 6. Vertical cut of $Z_{\mathrm{H}}$ (upper left panel), $Z_{\mathrm{DR}}$ (upper right panel), $\rho_{\mathrm{HV}}$ (middle left panel), $K_{\mathrm{DP}}$ (middle right panel), radial velocity (lower left panel) and hydrometeor classes (HC; lower right panel) taken at $5^{\circ}$ of azimuth on 21 February 2013 at 15:00 UTC.

b. Differential reflectivity calibration. In the present work, the $Z_{\mathrm{DR}}$ calibration is verified through the PPI collected at vertical incidence resorting to the hydrometeors properties (Gorgucci et al., 1999). As mentioned above, sweeps at vertical incidence with a rotating antenna are run operationally, thus providing 360 samples of vertical profiles every $10 \mathrm{~min}$. The average $Z_{\mathrm{DR}}$ in rain, taken only when the stratiform tail of the storm overpasses the radar site to avoid attenuation effects, provides the estimate of the calibration bias. In such conditions, the contribution of differential attenuation of a wet radome is negligible (Gorgucci et al., 2013). c. Ground clutter identification. The clutter filtering technique is based on a fuzzy logic approach that aims at discriminating non-weather from weather returns (Vulpiani et al., 2012). The output is a fuzzy variable expressing the degree of membership $d$ (ranging between 0 and 1) in the class "non-weather echo". Thus, the complementary $Q=1-d$ can be interpreted as the quality of the measurement, meaning that the higher the $Q$, the higher the data reliability.

d. Specific differential phase retrieval. The iterative moving-window range derivative scheme proposed by Vulpiani et al. (2012) is applied in the present work. It can be summarized through the following few steps: 
Event of 2013/02/21 at 1500 UTC - azimuth (deg): 5 elevation (deg): 6
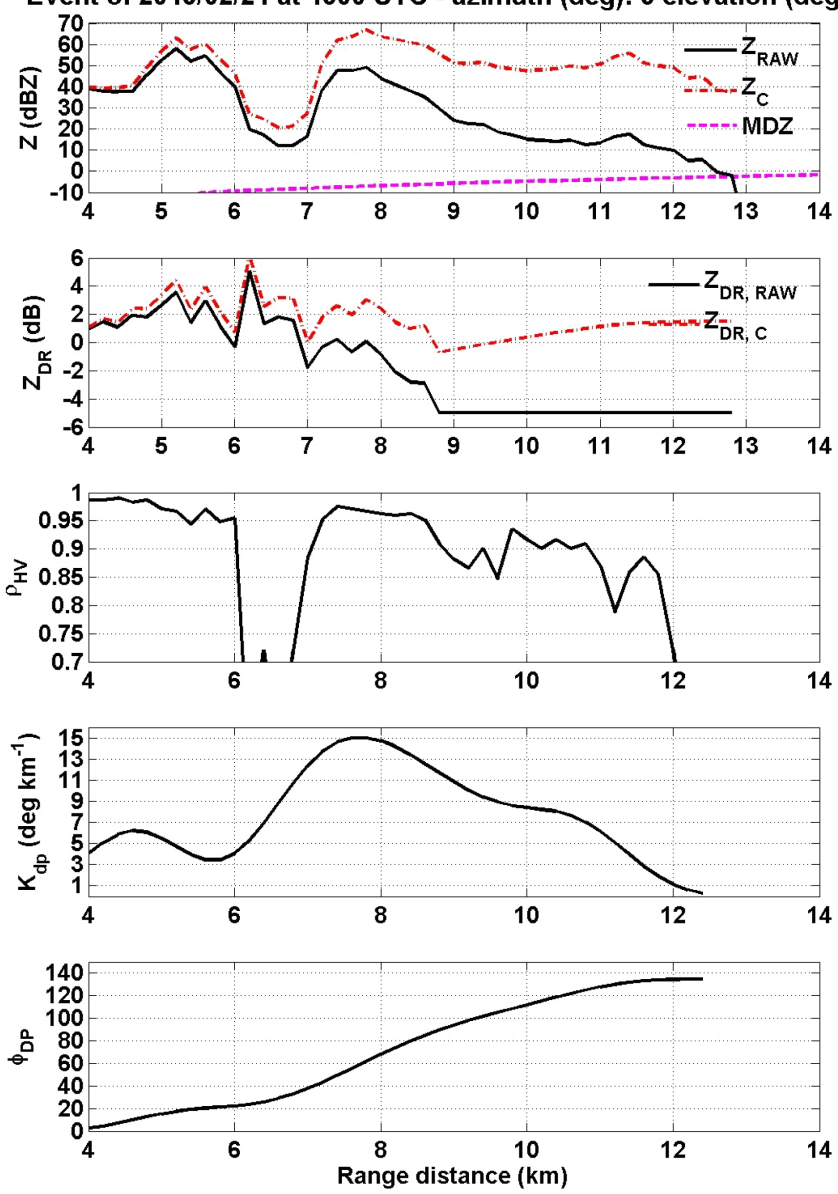

Figure 7. Range plots of the polarimetric radar parameters $Z_{\mathrm{H}}, Z_{\mathrm{DR}}, \rho_{\mathrm{HV}}, K_{\mathrm{DP}}$ and $\Phi_{\mathrm{DP}}$ taken at $5^{\circ}$ of azimuth and $6^{\circ}$ of antenna elevation on 21 February 2013 at 15:00 UTC. The two upper panels also show the attenuation-corrected reflectivity and differential reflectivity. The minimum detectable $Z_{\mathrm{H}}(\mathrm{MDZ})$ is also plotted on the upper panel.

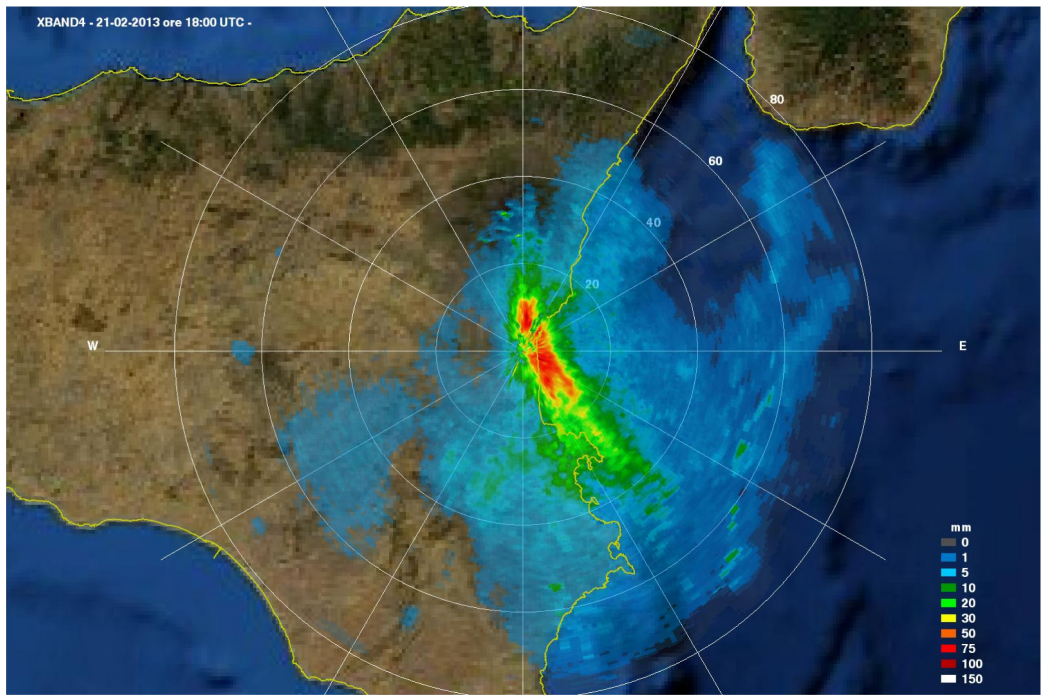

Figure 8. Map of cumulated precipitation as retrieved by the combined polarimetric algorithm between 15:00 and 18:00 UTC on 21 February 2013 
i. $K_{\text {DP }}$ retrieval (first guess). A first guess of the specific differential phase is retrieved from the raw differential phase through a finite-difference scheme over a given sized moving window.

ii. $K_{\mathrm{DP}}$ check. The out-of-range $K_{\mathrm{DP}}$ values are nullified.

iii. $\Phi_{\mathrm{DP}}$ reconstruction. The filtered differential phase is estimated as $\Phi_{\mathrm{DP}}(r)=2 \int_{0}^{r} K_{\mathrm{DP}}(s) \mathrm{d} s$

iv. $K_{\mathrm{DP}}$ retrieval (final guess). The final estimation of the specific differential phase $K_{\mathrm{DP}}$ is then obtained as a range derivative of the reconstructed $\Phi_{\mathrm{DP}}$.

Steps (iii)-(iv) are repeated iteratively to reduce the expected $K_{\mathrm{DP}}$ standard deviation $\sigma_{K_{\mathrm{DP}}}$. According to the uncertainty propagation theory, the standard deviation of the final $K_{\text {DP }}$ can be expressed (Vulpiani et al., 2012) as

$\sigma\left(K_{\mathrm{DP}}^{(I)}\right)=\frac{1}{\sqrt{2 N^{I}}} \frac{\sigma\left(\Psi_{\mathrm{DP}}\right)}{L}$,

where $N$ is the number of range gates contained in the $L$-sized moving window (i.e., $N=L / \Delta r, \Delta r$ being the range resolution), $I$ is the number of iterations (with $I \geq 1)$ and $\Psi_{\mathrm{DP}}$ is the total differential phase.It is worth mentioning that the retrieved differential phase is not affected by the system offset, which is removed through the derivative computation. This feature is particularly useful for attenuation correction purposes based on differential phase shift measurements.

Figure 2 shows the raw and reconstructed differential phase profiles observed on 21 August 2013 at 04:50 UTC. The offset of the raw $\Phi_{\mathrm{DP}}$, which is not an outcome of the processing algorithm and does not influence the applied processing (i.e., attenuation correction and rainfall estimation), has been roughly evaluated by an a posteriori comparison with the filtered $\Phi_{\mathrm{DP}}$ for easier interpretation of the results.

The length of the adopted moving window $(1 \mathrm{~km})$, is shorter with respect to that applied in Vulpiani et al. (2012) or that generally used in other $\Phi_{\mathrm{DP}}$ filtering scheme (e.g., Figueras i Ventura et al., 2013). This was necessary in order to capture the small-scale phase gradients (thus avoiding an excessive smoothing of rainfall fields), whereas, at the same time, the iterative scheme enables the smoothing of backscatter differential phase (Hubbert and Bringi, 1995) and noise effects.

e. Attenuation correction. The common polarimetric approach for compensating rain path attenuation is based on the assumed linearity between specific attenuation as well as differential attenuation and specific differential phase (Bringi et al., 1990; Testud et al., 2000), i.e., $A_{\mathrm{H}, \mathrm{DP}}=\gamma_{\mathrm{H}, \mathrm{DP}} K_{\mathrm{DP}}$. It is known that the coefficients $\gamma_{\mathrm{H}, \mathrm{DP}}$ are variable, depending on raindrop size, shape and temperature (Jameson, 1992; Matrosov et al., 2014). Despite the fact that several optimization approaches have been proposed (Carey et al., 2000; Bringi et al., 2001; Vulpiani et al., 2008), solutions that are totally reliable for operational applications are not yet available. The parameterization adopted in the present work was obtained from T-Matrix scattering simulations based on the 3 years of drop size distribution (DSD) observations collected in Rome (central Tyrrhenian coastline of Italy) (Adirosi et al., 2015), resulting in $\gamma_{\mathrm{H}}=0.29 \mathrm{~dB} \mathrm{deg}^{-1}, \gamma_{\mathrm{DP}}=0.048 \mathrm{~dB} \mathrm{deg}^{-1}$. According to the updated Koppen-Geiger climate classification (Peel et al., 2007; Rubel and Kottek, 2010), the central-southern Tyrrhenian coastline of Italy is climatologically similar to Sicily. It is worth specifying that attenuation is estimated until the slant range $r_{\mathrm{N}}$, that is the range gate corresponding to the altitude $H_{\mathrm{N}}=\mathrm{FLH}(m)-500$, where FLH stands for freezing layer height. At farther ranges, attenuation and differential attenuation accumulated until $r_{\mathrm{N}}$ are applied to correct reflectivity and differential reflectivity, respectively. For the sake of completeness, it must be specified that wet hail attenuation has not been compensated for. Indeed, it can be very tricky and uncertain, depending on many factors, including particle size, shape, as well as the water coat thickness that can modify the particle shape and fall orientation (Rasmussen and Heymsfield, 1987).

f. Rainfall estimation. The polarimetric rainfall algorithm proposed by Vulpiani and Baldini (2013), based on the use of reflectivity factor and specific differential phase, is applied in the present study. With the aim of gradually using $K_{\mathrm{DP}}$ at increasing rainfall intensities, the combined algorithm takes the form of a weighted sum

$R_{C}=w_{K} \cdot R_{K}+\left(1-w_{K}\right) \cdot R_{Z}$,

where $R_{Z}$ and $R_{K}$ are the rainfall estimates obtained by applying specific power laws to the lowest non-shielded radar bin of $Z_{\mathrm{H}}$ and $K_{\mathrm{DP}}$, respectively. To avoid hail contamination effects on $R_{Z}$, reflectivity was limited to the maximum value of $55 \mathrm{dBZ}$. The $R_{K}$ parameterization is based on the study carried out by Adirosi et al. (2015) $\left(R=14.69 K_{\mathrm{DP}}^{0.84}\right)$, whereas the Marshall and Palmer (1948) coefficients are adopted to derive $R_{Z}$.

The weight $w_{K}$ is defined as

$$
w_{K}= \begin{cases}0, & \text { if } K_{\mathrm{DP}} \leq 0.5 \\ 2 \cdot K_{\mathrm{DP}}-1, & \text { if } 0.5<K_{\mathrm{DP}}<1 \\ 1, & \text { if } K_{\mathrm{DP}} \geq 1 .\end{cases}
$$

g. Hydrometeor classification. The applied hydrometeor classification approach is based on the fuzzy logic 


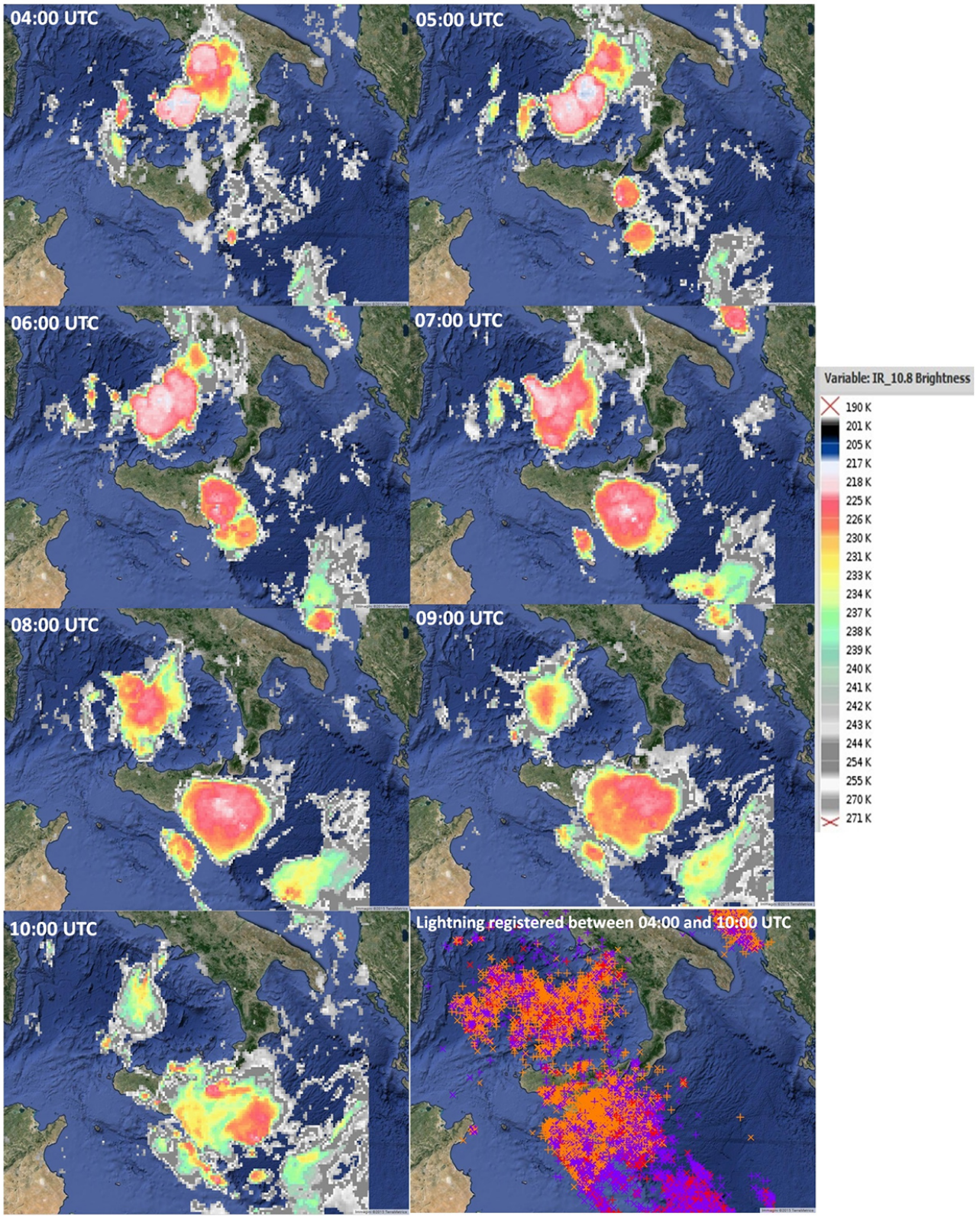

Figure 9. Brightness temperature at $10.8 \mu \mathrm{m}$ as retrieved on 21 August 2013 by Spinning Enhanced Visible and Infrared Imager (SEVIRI) instrument on board the Meteosat Second Generation (MSG) geostationary satellite.

scheme proposed by Liu and Chandrasekar (2000), adapted for X-band following Dolan and Rutledge (2009). The input parameters are the polarimetric radar observables $\left(Z_{\mathrm{H}}, Z_{\mathrm{DR}}, K_{\mathrm{DP}}, \rho_{\mathrm{HV}}\right)$ and the height of the melting layer. The algorithm attempts to identify the following six hydrometeor types: rain (a unique class for all types of liquid hydrometeor), wet snow, dry snow, graupel and small hail, hail and rain-hail mixture. When the aggregation step is uncertain, due to similar inference products, the de-fuzzyfication procedure is concluded labeling the radar echo as "not classified" (NC).

\section{Storm analysis}

\subsection{February 2013 case study}

The first precipitation event discussed here was observed on 21 February 2013. It was a winter convective system that hit Sicily, marginally causing a flash flood in Catania, located on the central-eastern coastline. Fortunately, most of the precipitation fell over the sea. According to press reports, hail was also observed. Looking at the brightness temperature images at $10.8 \mu \mathrm{m}$ shown on Fig. 3, it can be noted that around 15:00 UTC, a relatively high system (the cloud top 


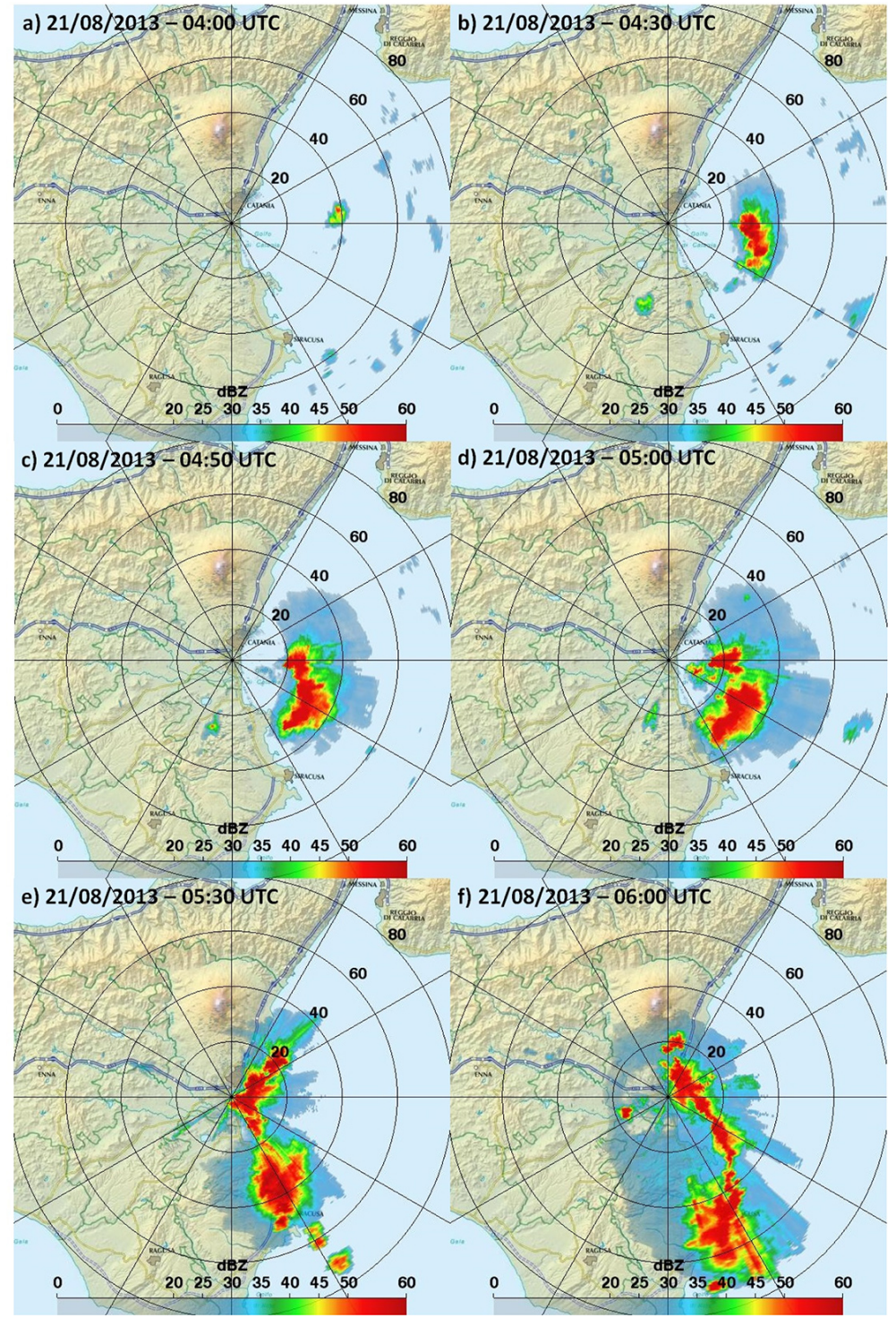

Figure 10. Vertical maximum intensity maps as retrieved on 21 August 2013 at 04:00, 04:30, 04:50, 05:00, 05:30 and 06:00 UTC.

temperature being lower than $220 \mathrm{~K}$ ) approached the Sicilian eastern coast, where it lasted about $3 \mathrm{~h}$. The lower left panel also shows the intense lightning observed by the LAMPINET network (Biron, 2009) between 15:00 and 18:00 UTC. The cross mark $(+)$ refers to positive charges, generally originated by the cloud top toward the ground (cloud to ground lightning, CG) or the cloud base (intra-cloud lightning, IC). The $\mathrm{x}$-mark $(\mathrm{X})$ refers to negative charges, generally originated by the cloud base toward the ground (CG), typically occurring during the mature stage of the storm. The map confirms that most of the convective activity developed close to Sicily and the Calabrian coastline. To identify and eventually compensate any calibration bias on $Z_{\mathrm{DR}}$, observations at vertical incidence are analyzed, avoiding wet radome attenuation conditions. Figure 4 shows the average of the 360 vertical profiles of $Z_{\mathrm{H}}, Z_{\mathrm{DR}}, \rho_{\mathrm{HV}}$ and $V$, sampled by rotating the antenna at vertical incidence at 16:50 UTC, when the stratiform tail of the storm passed over the radar site. Such profiles suggest that the height of the $0^{\circ}$ isothermal was $2100 \mathrm{~m}$ above the radar. Focusing on the differential reflectivity profile below the melting or in the snow region, a negligible calibration bias can be noticed (the average value of $Z_{\mathrm{DR}}$ computed in rain is $0.02 \mathrm{~dB}$, whereas the corresponding standard deviation is about $0.33 \mathrm{~dB}$ ). As expected, the peak of $Z_{\mathrm{H}}$ occurs where the melting creates the largest drops, whereas the minimum of $\rho_{\mathrm{HV}}$ is located where the hydrometeor population becomes more heterogeneous (Zrnić et al., 1994) typically below the peak of $Z_{\mathrm{H}}$ (Baldini and Gorgucci, 2006). It is worth specifying that the fluctuations in the very first range gates are likely caused by the TR (transmit/receive) limiter 


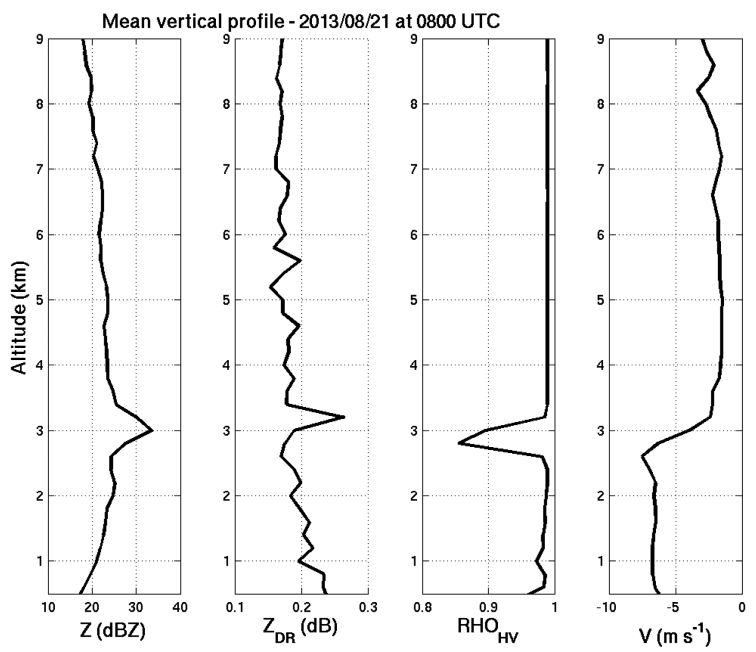

Figure 11. Mean vertical profiles of reflectivity, differential reflectivity, correlation coefficient and Doppler velocity observed on 21 August 2013 at 08:00 UTC.

mismatch between the horizontal and vertical channels. With reference to Fig. 5, showing some frames of vertical maximum intensity (VMI) ${ }^{1}$ obtained by the reflectivity volume corrected for attenuation, around 15:00 UTC the storm was characterized by a localized intense core in the proximity of the radar site with reflectivity values exceeding $60 \mathrm{dBZ}$. The rest of the radar image shows light to moderate values of reflectivity. A northward shielded sector, originated by signal extinction, is quite evident on the tail of the convective core. At 16:00 UTC, the VMI image shows lower reflectivity values, likely related to wet radome effects originated in the storm core located approximately above the radar site. Due to its transient nature and the extensive use of $K_{\mathrm{DP}}$, wet radome attenuation is not expected to remarkably affect rainfall estimation. However, further efforts will be devoted to the operational compensation of such effects through the implementation of self-consistency approaches (Gorgucci et al., 2013) or comparison with external nearby rain measurements (Bechini et al., 2010).

The precipitation nucleus moved southeast, leaving the city of Catania around 17:00 UTC. Focusing on the shielded azimuthal sector, which manifested at 15:00 UTC, Fig. 6 shows the pseudo-RHIs (range height intensities) of the radar observables at $5^{\circ}$ of azimuth, which are not affected by beam blocking, as outlined by the visibility map shown in Fig. 1 . Two intense precipitation cores are evident from the reflectivity slice, respectively located at about 5 and $8 \mathrm{~km}$ from the radar site. They were responsible for the signal extinction, which mainly affected the lower tilts. The second reflectivity core exceeds the presumed freezing layer height by at least

\footnotetext{
${ }^{1}$ The vertical maximum intensity is a polar 2-D map of $Z_{\mathrm{H}}$ obtained by taking the maximum value of the reflectivity volume with respect to the vertical (i.e., varying the antenna elevation).
}

$1 \mathrm{~km}$, prefiguring the presence of a hail nucleus. Although the adopted scan inhibits the sampling above about $1.8 \mathrm{kma}$ a.s.1. at short-range distances, similar behavior can be argued for the first core by resorting to physical continuity. Within the first reflectivity nucleus, high values of differential reflectivity are found below $1 \mathrm{~km}$ a.s.l. The corresponding values of $K_{\mathrm{DP}}$ (up to $6^{\circ} \mathrm{km}^{-1}$ ) and $\rho_{\mathrm{HV}}$ (mostly below 0.95 ) might be congruent with the coexistence of rain and hail precipitation. Within the second convective core, values of $Z_{\mathrm{DR}}$ larger than $1 \mathrm{~dB}$ are also found above the $0^{\circ}$ isothermal, topped by low values of $\rho_{\mathrm{HV}}$, likely related to an intrusion of supercooled water drops. At altitudes lower than the presumed melting layer base, the noticeable decrease of $\rho_{\mathrm{HV}}$ can be referred to a rain and hail mixture with a high water fraction, as inferable by the corresponding values of $K_{\mathrm{DP}}$ and confirmed by the results of the classification algorithm (shown in the lower right panel of Fig. 6). Figure 7, showing the range plots at $6^{\circ}$ of antenna elevation for the same azimuth, points out the effects of attenuation. The swift decrease of $Z_{\mathrm{H}}$, reaching the minimum detectable $Z_{\mathrm{H}}(\mathrm{MDZ})$ at about $13 \mathrm{~km}$ from the radar, where the phase shift exceeded $130^{\circ}$ in just an $8 \mathrm{~km}$ path, culminated with total extinction. It is worth noting the factitious asymptotic behavior of measured $Z_{\mathrm{DR}}$ which dropped down to the bottom of the scale $(-5 \mathrm{~dB})$ due to attenuation. Finally, Fig. 8 shows the map of precipitation cumulated in $3 \mathrm{~h}$, as retrieved by the combined polarimetric algorithm described by Eq. (3). The precipitation peak observed on land is very close to the radar site. Only 31 tipping bucket rain gauges among the 221 distributed in Sicily registered precipitation (at least $0.2 \mathrm{~mm} \mathrm{~h}^{-1}$ ), the storm mainly having affected the coastline. The rain gauge located in Catania registered about $60 \mathrm{~mm}$ in $1 \mathrm{~h}$ (from 15:00 to 16:00 UTC) and about $70 \mathrm{~mm}$ in $1.5 \mathrm{~h}$ (from 15:00 to 16:30 UTC). The other available gauges registered less than $20 \mathrm{~mm}$ in $3 \mathrm{~h}$. Based on the comparison with the available rain gauges, the accuracy of the combined rainfall algorithm $R_{C}$ has been evaluated on an hourly basis in terms of mean error $\langle\varepsilon\rangle=\left\langle R_{\mathrm{R}}-R_{\mathrm{G}}\right\rangle$, error standard deviation $\sigma=\left\langle\left(R_{\mathrm{R}}-R_{\mathrm{G}}\right)^{2}\right\rangle^{1 / 2}$, root-meansquare error $(\mathrm{RMSE})=\sqrt{\left(\left\langle\varepsilon^{2}+\sigma^{2}\right\rangle\right)}$, fractional standard error $(\mathrm{FSE})=\mathrm{RMSE} /\left\langle R_{\mathrm{G}}\right\rangle$, and bias $=\left\langle R_{\mathrm{R}}\right\rangle /\left\langle R_{\mathrm{G}}\right\rangle$. The angle brackets denote the spatial and temporal average operator, whereas $R_{\mathrm{R}}$ and $R_{\mathrm{G}}$ refer to the radar estimate and gauge observation, respectively. The results, summarized in Table 1, point out the improvement obtained by the combined polarimetric technique in terms of RMSE, FSE, and bias if compared with the conventional $Z_{\mathrm{H}}-R$ relationship. It is worth mentioning that $R_{K}$ slightly outperformed $R_{C}$ in terms of bias, whereas the RMSE was higher because of the error standard deviation. The impact of $K_{\mathrm{DP}}$ in the rainfall estimation process through the composite algorithm can be evaluated by quantifying the relative occurrences of $K_{\mathrm{DP}}$ values. In this perspective it was found $K_{\mathrm{DP}}<0.5 \mathrm{deg} \mathrm{km}^{-1}$ in about $73 \%$ of the cases, $0.5<K_{\mathrm{DP}}<1 \mathrm{deg} \mathrm{km}^{-1}$ in about $16 \%$ and $K_{\mathrm{DP}}>1 \mathrm{deg} \mathrm{km}{ }^{-1}$ in the remaining $11 \%$. 
Table 1. Error scores computed on hourly cumulated rainfall for the event observed on 21 February 2013. RMSE refers to the root-meansquare error; FSE refers to the fractional standard error; "adim" represents adimensional ratios.

\begin{tabular}{cccccc}
\hline Algorithm & $\bar{\varepsilon}(\mathrm{mm})$ & $\sigma_{\varepsilon}(\mathrm{mm})$ & RMSE $(\mathrm{mm})$ & FSE (adim) & Bias (adim) \\
\hline$R_{Z}$ & -1.62 & 2.12 & 2.65 & 0.64 & 0.61 \\
$R_{K}$ & -0.36 & 2.64 & 2.63 & 0.64 & 0.91 \\
$R_{C}$ & -0.81 & 2.16 & 2.28 & 0.55 & 0.80
\end{tabular}
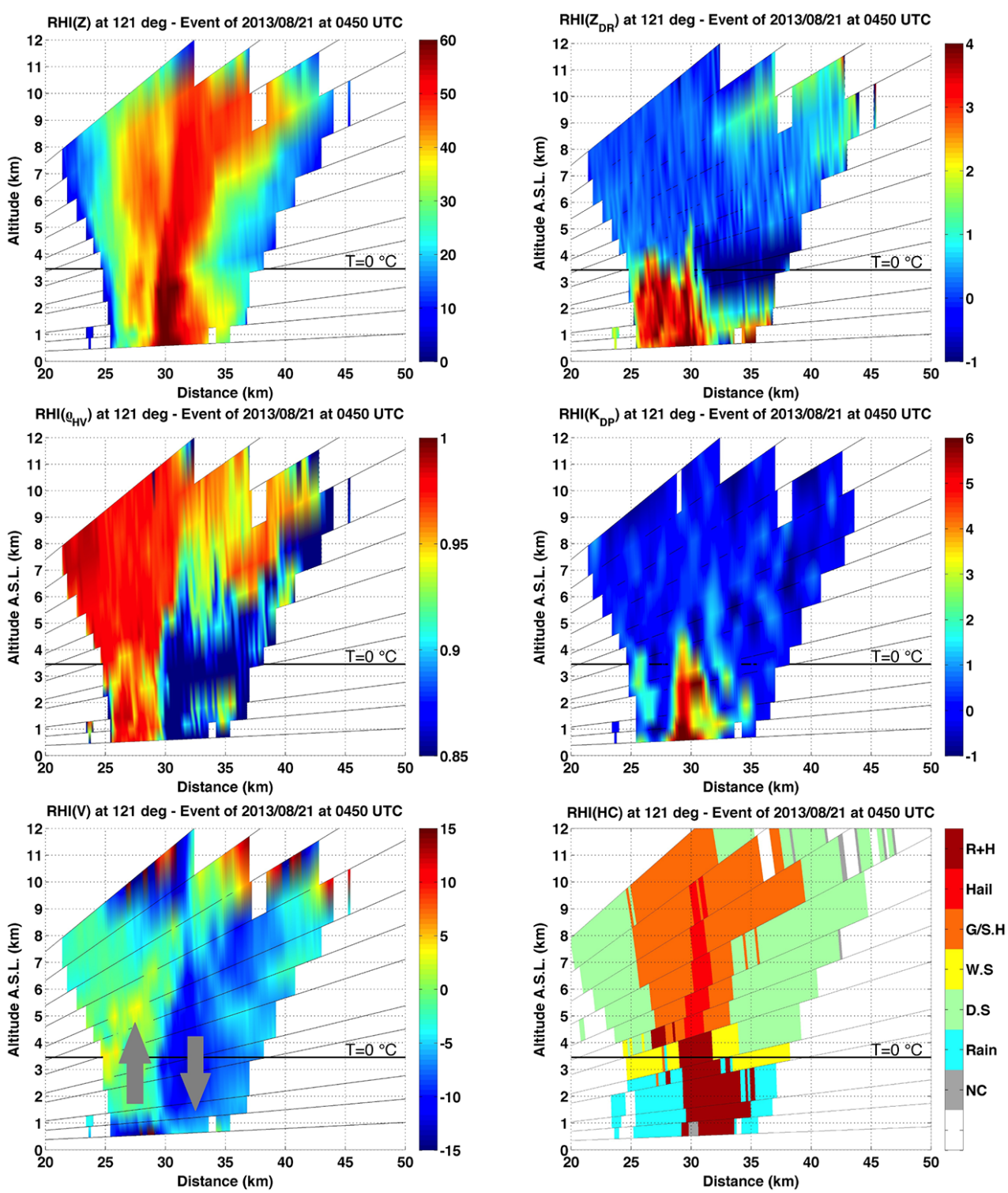

Figure 12. Vertical cut of $Z_{\mathrm{H}}$ (upper left panel), $Z_{\mathrm{DR}}$ (upper right panel), $\rho_{\mathrm{HV}}$ (middle left panel), $K_{\mathrm{DP}}$ (middle right panel), radial velocity (lower left panel) and hydrometeor classes (lower right panel) taken at 121 ${ }^{\circ}$ of azimuth on 21 August 2013 at 04:50 UTC.

\subsection{August 2013 case study}

A Mediterranean low pressure system was the origin of the severe mesoscale convective system that hit Sicily on $21 \mathrm{Au}-$ gust 2013. The resulting intense precipitation flooded sev- eral towns on the eastern coast, including Syracuse. The system originated around 04:00 UTC and lasted about $6 \mathrm{~h}$. The maximum precipitation amount, registered in just $2 \mathrm{~h}$ by the rain gauge located in Syracuse, exceeded $180 \mathrm{~mm}$, whereof $135 \mathrm{~mm}$ was observed in just $1 \mathrm{~h}$ and hail was also reported 

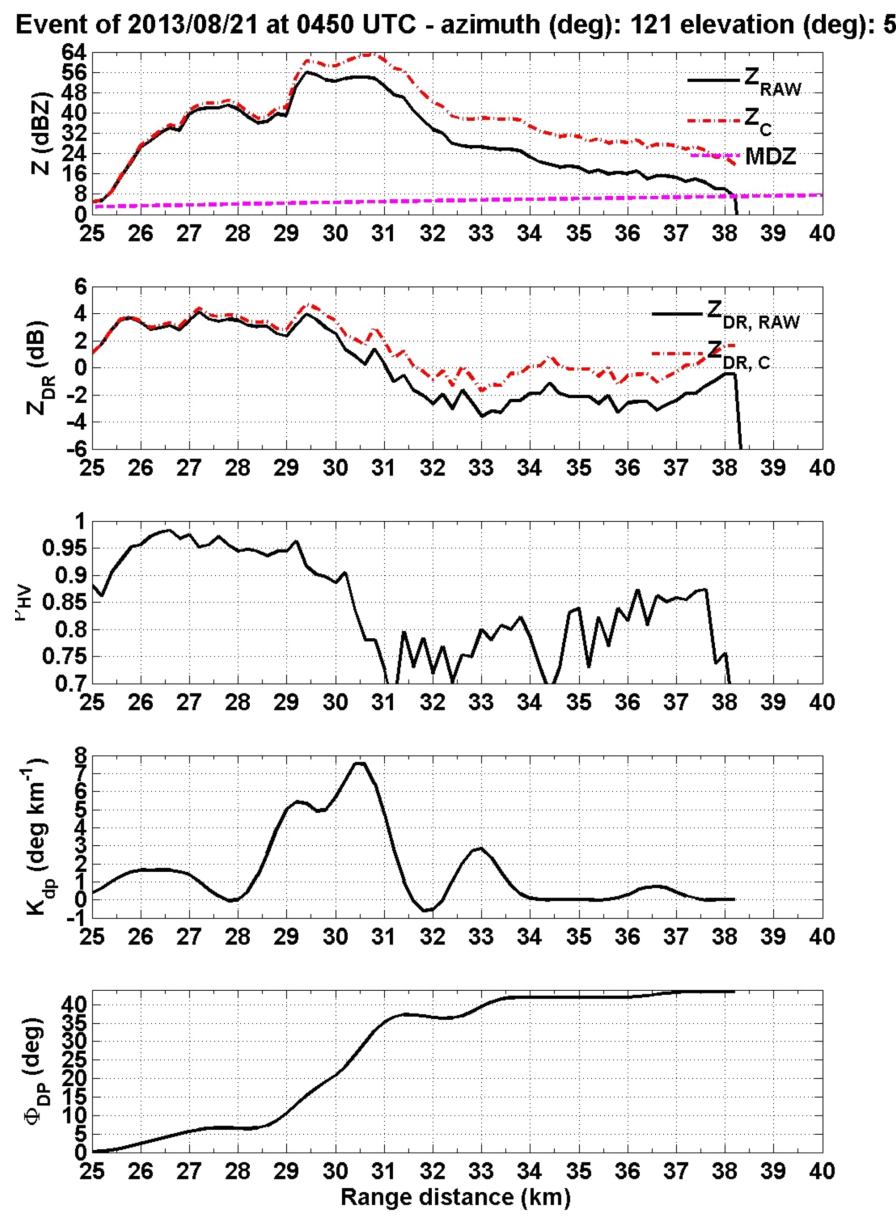

Figure 13. Range plots of the polarimetric radar parameters $Z_{\mathrm{H}}, Z_{\mathrm{DR}}, \rho_{\mathrm{HV}}, K_{\mathrm{DP}}$ and $\Phi_{\mathrm{DP}}$ taken at $121^{\circ}$ of azimuth and $5^{\circ}$ of antenna elevation on 21 August 2013 at 04:50 UTC. The two upper panels also show the attenuation-corrected reflectivity and differential reflectivity. The minimum detectable $Z_{\mathrm{H}}(\mathrm{MDZ})$ is also plotted on the upper panel.

at the ground. Most of the precipitation fell over the sea. Figure 9 shows some time frames of the brightness temperature at $10.8 \mu \mathrm{m}$ as retrieved by MSG. The embryo of the convective cloud formed around 04:00 UTC over the Ionian Sea. After $1 \mathrm{~h}$, two main convective systems were clearly identifiable before they merged around 06:00 UTC, producing the maximum effects overground between 06:00 and 08:00 UTC. The dissipation phase started around 09:00 UTC and concluded after about $1 \mathrm{~h}$. The lower left panel of Fig. 9 shows the registered lightning strikes. The radar observations allow the storm development to be captured, especially the northern part, as it can be seen in Fig. 10, showing some crucial time frames in terms of VMI. At 04:00 UTC, a smallsized convective cell was identifiable eastward. After half an hour, the storm reached a fairly mature stage, with a reflectivity core largely exceeding 50 dBZ. Around 04:50 UTC, the effects of signal extinction became manifest eastward at about $40 \mathrm{~km}$ from the radar site. The shielding effect was deeper $10 \mathrm{~min}$ later as a consequence of further storm development. The storm assumed a multi-cellular structure around 05:30 UTC, when the southern cell started to hit Syracuse. As can be noted by Fig. 11, the approximate freezing layer height (FLH) was located around $3.4 \mathrm{~km}$ a.s.l. at around 08:00 UTC, according to the radar observations collected at vertical incidence. Figure 11 also shows that $Z_{\mathrm{DR}}$ was affected by a relatively negligible bias, being within $0.2 \mathrm{~dB}$, with a standard deviation of about $0.13 \mathrm{~dB}$. The vertical section of the polarimetric radar measurements was analyzed at 04:50 UTC for the 121st and 122nd azimuthal angles, shown in Figures 12 and 14, respectively. Focusing first on azimuth 121 , it is worth noting the reflectivity core located at about $30 \mathrm{~km}$ from the radar which extended above $10 \mathrm{~km}$ in height. High values of $Z_{\mathrm{DR}}$ below the presumed freezing layer, noticeable till the reflectivity core, are ascribable to large drops, as also documented by the corresponding correlation coefficient, mostly ranging around 0.95 . The intrusion of liquid water dropping above the FLH is particularly evident through the $Z_{\mathrm{DR}}$ column (i.e., vertical distribution of positive $Z_{\mathrm{DR}}$ values) in correspondence with the center of the reflectivity core (Kumjian et al., 2014). The correlated $K_{\text {DP }}$ column fur- 

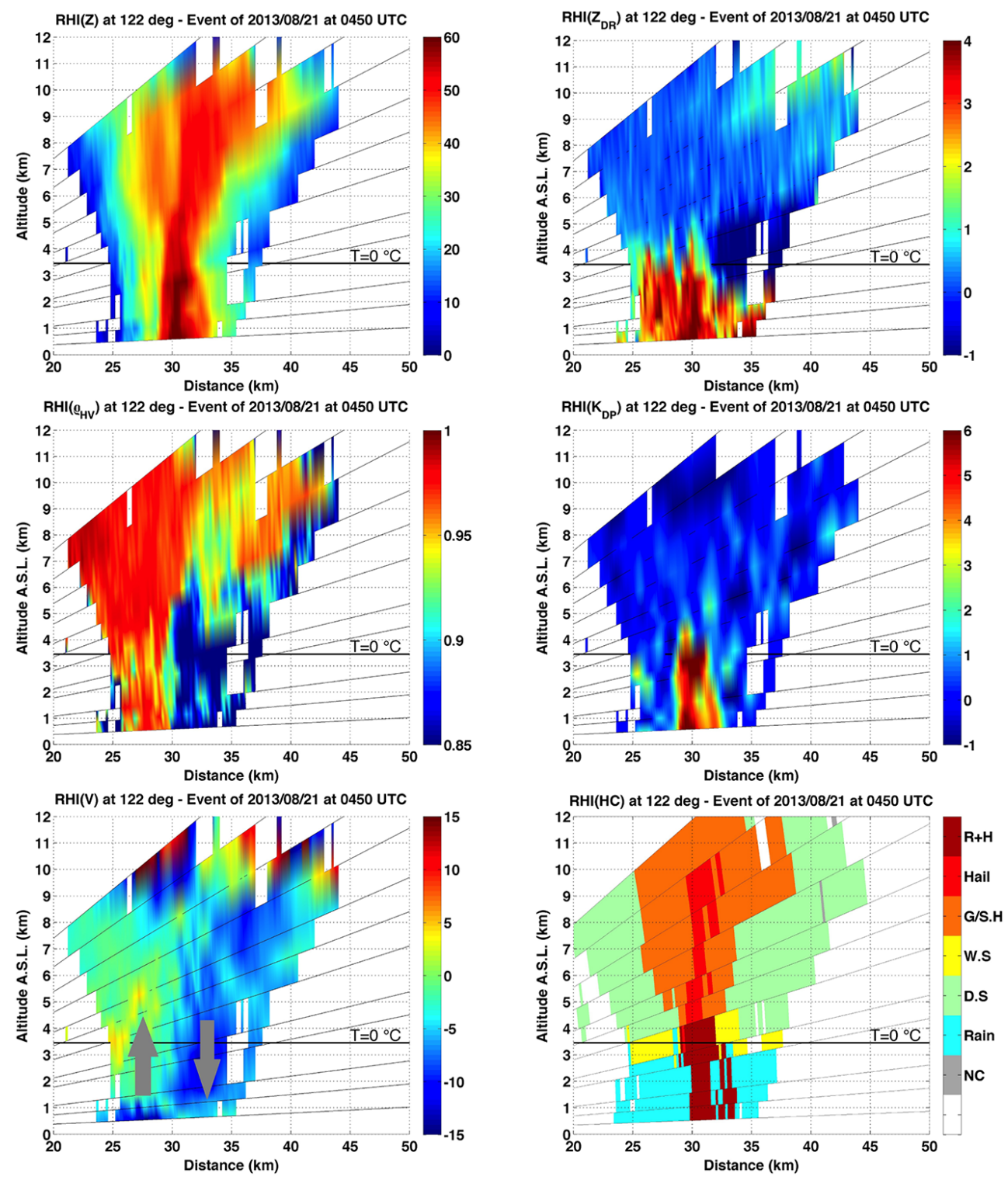

Figure 14. Vertical cut of $Z_{\mathrm{H}}$ (upper left panel), $Z_{\mathrm{DR}}$ (upper right panel), $\rho_{\mathrm{HV}}$ (middle left panel), $K_{\mathrm{DP}}$ (middle right panel), radial velocity (lower left panel) and hydrometeor classes (lower right panel) taken at $122^{\circ}$ of azimuth on the 21 August 2013 at 04:50 UTC.

ther testifies to the relevant liquid water fraction above the FLH. According to the schematic circulation superimposed on the vertical cut of radial velocity, the strong updraft on the left side of the reflectivity core triggered the supercooling of large drops that turned into hailstones by freezing on condensation nuclei. Beyond the reflectivity core, $Z_{\mathrm{DR}}$ was clearly affected by differential attenuation. More interestingly, the deep depression of $\rho_{\mathrm{HV}}$ can be attributed to nonuniform beam filling induced by the hail-rain precipitation mixture, as identified by the adopted hydrometeor classification scheme. In this respect, it is worth emphasizing again that the correlation coefficient is routinely corrected for low SNR through the noise power measured operationally after each volumetric scan, as described in Sect. 2.2.
Figure 13 shows the range plots of the radar observables at $5^{\circ}$ of antenna elevation for the same azimuth as in Fig. 12. The precipitation peak, located between 29 and $31 \mathrm{~km}$ from the radar, is responsible for about $12 \mathrm{~dB}$ of attenuation, whereas the estimated differential attenuation is about $2 \mathrm{~dB}$. The corresponding relatively high values of $K_{\mathrm{DP}}$ are symptomatic of high liquid water fraction. Consequently, the abrupt decrease suffered by the correlation coefficient through the precipitation peak where it dropped down to about 0.75 , even though the reflectivity is clearly higher than the estimated MDZ (SNR is above $12 \mathrm{~dB}$ within $35 \mathrm{~km}$ ), must be ascribed to the heterogeneity of the hydrometeor population within the radar beam. As might be expected, the vertical cut taken at azimuth 122 shows similar characteristics, 
Table 2. Error scores computed on hourly cumulated rainfall for the event observed on 21 August 2013. RMSE refers to the root-mean-square error; FSE refers to the fractional standard error; "adim" represents adimensional ratios.

\begin{tabular}{|c|c|c|c|c|c|c|c|}
\hline Algorithm & $\bar{\varepsilon}(\mathrm{mm})$ & $\sigma_{\varepsilon}$ & $(\mathrm{mm})$ & RMSE & $(\mathrm{mm})$ & FSE (adim) & Bias (adim) \\
\hline$R_{Z}$ & -2.68 & & 12.41 & & 12.59 & 1.71 & 0.63 \\
\hline$R_{K}$ & 0.88 & & 10.44 & & 10.39 & 1.41 & 1.12 \\
\hline$R_{C}$ & -0.62 & & 9.97 & & 9.97 & 1.36 & 0.92 \\
\hline
\end{tabular}

Event of 2013/08/21 at 0450 UTC - azimuth (deg): 122 elevation (deg): 5
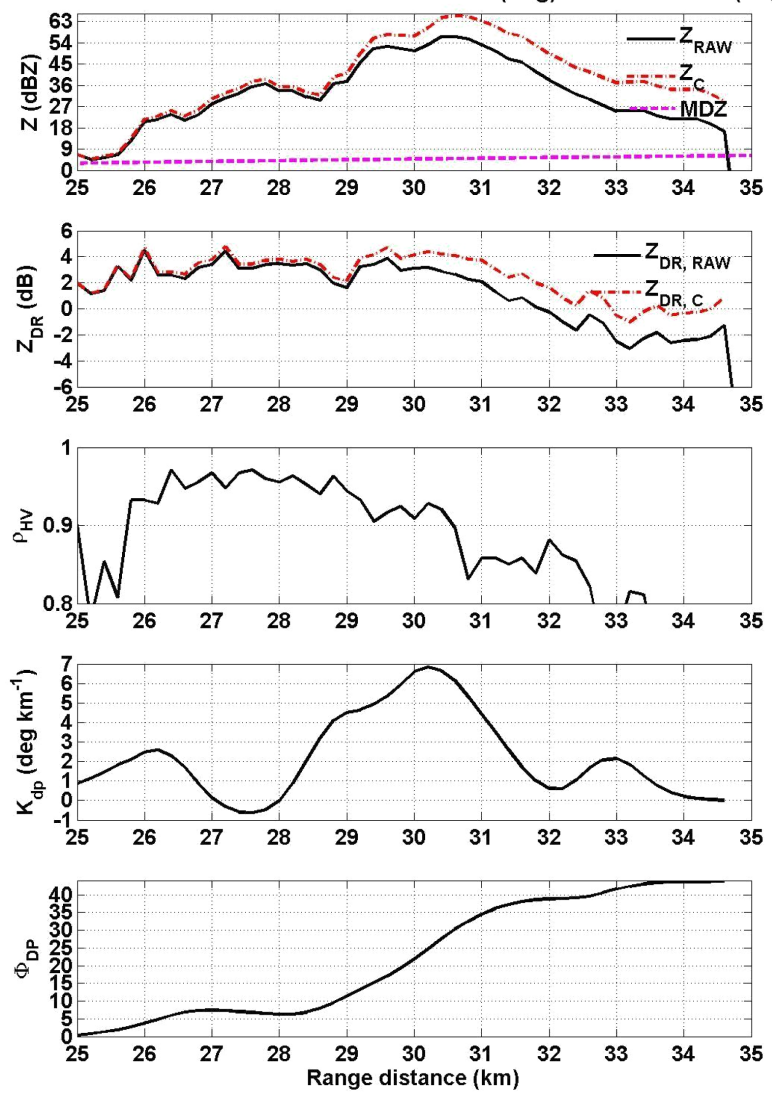

Figure 15. Range plots of the polarimetric radar measurements $Z_{\mathrm{H}}$, $Z_{\mathrm{DR}}, \rho_{\mathrm{HV}}, K_{\mathrm{DP}}$ and $\Phi_{\mathrm{DP}}$ taken at $122^{\circ}$ of azimuth and $3^{\circ}$ of antenna elevation on 21 August 2013 at 04:50 UTC. The two upper panels also show the attenuation-corrected reflectivity and differential reflectivity. The minimum detectable $Z_{\mathrm{H}}$ (MDZ) is also plotted on the upper panel.

although some features look more pronounced. Looking at Fig. 14, three $Z_{\text {DR }}$ columns extend above the FLH. With respect to those in Fig. 12 they appear much more smeared. Contextually, the specific differential phase exceeds $5^{\circ} \mathrm{km}^{-1}$ within the $K_{\text {DP }}$ column that can be found at $30 \mathrm{~km}$ distance. Moreover, the column is within a region in which $\rho_{\mathrm{HV}}$ is low. Accordingly, the hydrometeor classification algorithm detects rain-hail mixture or just hail in correspondence with the reflectivity core, respectively, below and above the FLH. As shown in Fig. 15, the range profiles taken at $5^{\circ}$ of antenna el-

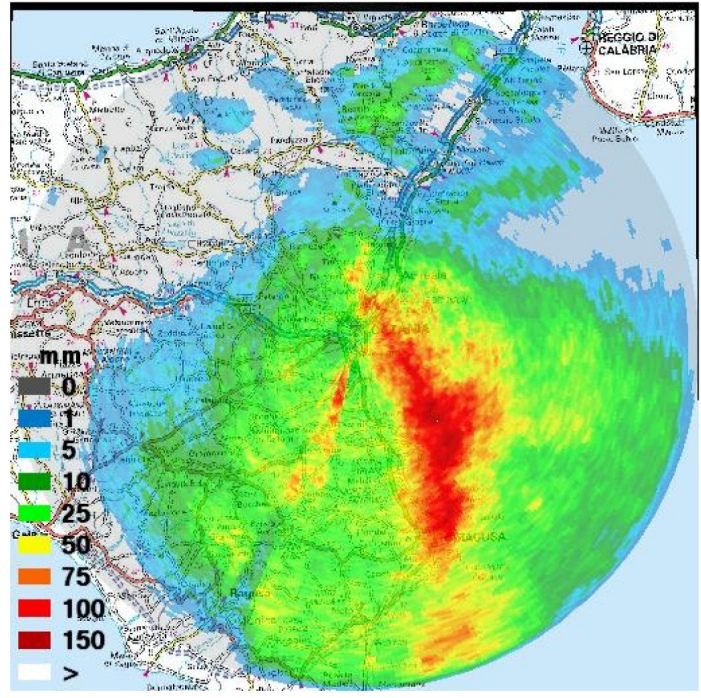

Figure 16. Map of cumulated precipitation as retrieved by the combined polarimetric algorithm between 04:00 and 10:00 UTC on 21 August 2013.

evation highlight a main precipitation peak, generating about $6 \mathrm{~dB}$ of attenuation cumulated in about $4 \mathrm{~km}$. The profile of $K_{\text {DP }}$ outlines two secondary precipitation peaks, accounting for the rest of the retrieved attenuation, which sums in total $10 \mathrm{~dB}$. Also in this case, the correlation coefficient remarkably decreases within the convective core, dropping to 0.85 . The map of precipitation accumulated in $6 \mathrm{~h}$ is shown in Fig. 16. The image clearly outlines that most of the precipitation was observed on the southeastern coast, with a peak around the city of Syracuse about $60 \mathrm{~km}$ from the radar site. The adopted combined rainfall algorithm retrieved the precipitation pattern fairly well despite the fact that the peak was underestimated by about $30 \%$, i.e., $135 \mathrm{vs.} 186 \mathrm{~mm}$. The overall error analysis summarized in Table 2 shows a remarkable improvement obtained by the approaches employing $K_{\mathrm{DP}}$, especially in the presence of rain-hail mixture, when compared to the conventional $Z_{\mathrm{H}}-R$ inversion technique, especially $R_{C}$, outperforming both $R_{Z}$ and $R_{K}$. In this case the relative impact of $K_{\mathrm{DP}}$ in the performance of $R_{C}$ was higher than for the precipitation event formerly discussed. $R_{K}$ was used in about $16 \%$ of the cases $\left(K_{\mathrm{DP}}>1 \mathrm{deg} \mathrm{km}^{-1}\right)$, whereas it was used in combination with $R_{Z}$ in about $23 \%$ (for $0.5<K_{\mathrm{DP}}<1 \mathrm{deg} \mathrm{km}^{-1}$ ). 


\section{Conclusions}

This manuscript has documented the effective monitoring of intense precipitation events in the Mediterranean area using an operational X-band dual-polarization weather radar operated in Catania (Sicily, Italy) by the Italian Department of Civil Protection. Two severe hail-bearing storms that occurred in 2013 in south Italy have been described in terms of their polarimetric radar signatures and estimated rainfall fields. On 21 February 2013, a winter convective system originating in the Tyrrhenian Sea caused a flash flood in the city of Catania. Due to an optimal radar location, it was possible to effectively reconstruct the storm characteristics in spite of the known limitation of X-band systems due to attenuation. A few cases of signal extinction, caused by close-range hail core generating significant differential phase shift in a very short-range path, were documented. However, intense precipitation rarely occurred above the radar, keeping the influence of radome attenuation generally negligible regarding rainfall estimation, which benefited from the extensive use of $K_{\text {DP. }}$ The second storm event, a mesoscale convective system originated by a Mediterranean low pressure system, was observed on 21 August 2013. It lasted about $6 \mathrm{~h}$, with a precipitation peak of $186 \mathrm{~mm}$ registered in just $2 \mathrm{~h}$ in Syracuse which, consequently, was flooded. Although the use of $K_{\mathrm{DP}}$ can mitigate issues of rain estimation in the presence of a hail-rain mixture (Matrosov et al., 2013), analysis of storm dynamics requires the use of a set of dual-polarization measurements that include reflectivity and differential reflectivity that, at X-band, are attenuated by propagation along precipitation. Attenuation and differential attenuation were compensated through differential phase measurements, properly processed by means of an iterative approach using a shortlength moving window, enabling effective capture of the intrinsic small-scale storm characteristics. The comparative analysis of the polarimetric radar observations, by means of some vertical cut of the volumetric observations, enabled us to infer the triggering hail formation and precipitation process during the mature phase of the convective system. A fuzzy logic hydrometeor classification algorithm confirmed the occurrence of a rain-hail precipitation mixture, which likely caused the anomalous drop of the correlation coefficient. The precipitation fields were reconstructed fairly well using a combined polarimetric rainfall algorithm based on reflectivity and specific differential phase, which clearly outperformed the conventional $Z_{\mathrm{H}}-R$ inversion technique. In summary, it has been shown that, once a proper processing chain is applied, X-band dual-polarization radar can be an effective tool for monitoring and understanding the evolution of rapidly evolving precipitation events that frequently occur in the Mediterranean area, providing information that can help decision makers adopt appropriate risk mitigation measures.
Acknowledgements. L. Baldini and N. Roberto acknowledge the support of the agreement between CNR-ISAC and DPC for 2014.

Edited by: F. S. Marzano

\section{References}

Adirosi, E., Baldini, L., Roberto, N., Vulpiani, G., and Russo, F.: Using disdrometer measured raindrop size distributions to establish weather radar algorithms, AIP Conference Proceedings, 1648, 110-128, available at: http://scitation.aip.org/content/aip/ proceeding/aipcp/10.1063/1.4912476, last access: 3 November 2015.

Anagnostou, E. N., Anagnostou, M. N., Krajewski, W. F., Kurger, A., and Mirovsky, B. J.: High-resolution rainfall estimation from X-band polarimetric radar measurements, J. Hydrometeorol., 5, 110-128, 2004.

Anagnostou, M. N., Kalogiros, J., Anagnostou, E. N., Tarolli, M., Papadopoulus, A., and Borga, M.: Performance evaluation of high-resolution rainfall estimation by X-band dual-polarization radar for flash flood applications in mountainous basins, J. Hydrol., 394, 4-16, 2010.

Atlas, D. and Ludlam, F. H.: Multi-wavelength radar reflectivity of hailstorms, Q. J. Roy. Meteor. Soc., 87, 523-534, 1961.

Aydin, K., Seliga, T. A., and Bringi, V. N.: Differential radar scattering properties of model rain hail and mixed-phase hydrometeors, Radio Sci., 19, 58-66, 1984.

Aydin, K., Seliga, T. A., and Balaji, V.: Remote sensing of hail with a dual linear polarization radar, J. Clim. Appl. Meteorol., 34, 404-410, 1986.

Baldini, L. and Gorgucci, E.: Identification of the melting layer through dual-polarization radar measurements at vertical incidence, J. Atmos. Ocean. Tech., 23, 829-839, 2006.

Bechini, R., Chandrasekar, V., Cremonini, R., and Lim, S.: Radome attenuation at X-band radar operations, in: Proc. 6th European Conf. on Radar in Meteorology and Hydrology: Adv. in Radar Technology, 6-10 September 2010, Sibiu, Romania, 2010.

Biron, D.: LAMPINET - lightning detection in Italy, in: Lightning: Principles, Instruments and Applications, edited by: Betz, H. D., Schumann, U., and Laroche, P., Springer, Dordrecht, the Netherlands, 141-159, 2009.

Bringi, V. N., Seliga, T. A., and Aydin, K.: Hail detection with a differential reflectivity radar, Science, 225, 1145-1157, 1984.

Bringi, V. N., Chandrasekar, V., Balakrishnan, N., and Zrnić, D. S.: An examination of propagation effects in rainfall on radar measurements at microwave frequencies, J. Atmos. Ocean. Tech., 7, 829-840, 1990.

Bringi, V. N. and Chandrasekar, V.: Polarimetric doppler weather radar, Cambridge University Press, Cambridge, UK, 636 pp., 2001.

Bringi, V. N., Keenan, T., and Chandrasekar, V.: Correcting C-band radar reflectivity and differential refelctivity data for rain attenuation: a self-consistent method with constraints, IEEE T. Geosci. Remote, 39, 1906-1915, 2001.

Carey, L. D., Rutledge, S. A., and Ahijevych, D. A.: Correcting propagation effects in C-band polarimetric radar observations of tropical convection using differential propagation phase, J. Appl. Meteorol., 39, 1405-1433, 2000. 
Cook, B.: Hail determination by radar analysis, Mon. Weather Rev., 86, 435-438, 1958.

Dolan, B. and Rutledge, S. A.: A theory-based hydrometeor identification algorithm for X-Band polarimetric radars, J. Atmos. Ocean. Tech., 26, 2071-2088, 2009.

Douglas, R. H. and Hitschfeld, W.: Studies of Alberta hailstorms, 1957, Tech. Rep. MW-27, Stormy Weather Group, McGill University, Montreal, Canada, 79 pp., 1958.

Eccles, P. J. and Atlas, D.: A dual-wavelength radar hail detector, J. Appl. Meteorol., 12, 847-854, 1973.

Figueras i Ventura, J., Honore, F., and Tabary, P.: X-band polarimetric weather radar observations of a hailstorm, J. Atmos. Ocean. Tech., 30, 2143-2151, 2013.

Gorgucci, E., Scarchilli, G., and Chandrasekar, V.: A procedure to calibrate multiparameter weather radar using properties of the rain medium, IEEE T. Geosci. Remote, 37, 269-276, 1999.

Gorgucci, E., Bechini, R., Baldini, L., Cremonini, R., and Chandrasekar, V.: The influence of antenna radome on weather radar calibration and its real-time assessment, J. Atmos. Oceanic Technol., 30, 676-689, 2013

Heinselman, P. L. and Ryzhkov, A. V.: Validation of polarimetric hail detection, Weather Forecast., 21, 839-850, 2006.

Hubbert, J. and Bringi, V. N.: An iterative filtering technique for the analysis of copolar differential phase and dual-frequency radar measurements, J. Atmos. Oceanic Technol., 12, 643-648, 1995.

Illingworth, A. J., Goddard, J. W. F., and Cherry, S. M.: Polarization radar studies of precipitation development in convective storms, Q. J. Roy. Meteor. Soc., 113, 469-489, 1987.

Jameson, A. R.: The effect of temperature on attenuation-correction schemes in rain using polarization propagation differential phase shift, J. Appl. Meteor.,31, 1106-1118, 1992.

Knight, C. A. and Knight, N. C.: The falling behaviour of hailstones, J. Atmos. Sci., 7, 672-681, 1970.

Kumjian, M. R., Khain, A. P., Benmoshe, N., Ilotoviz, E., Ryzhkov, A. V., and Phillips, V. T. J.: The anatomy and physics of ZDR columns: Investigating a polarimetric radar signature with a spectral bin microphysical model, J. Appl. Meteorol. Clim., 53, 1820-1843, 2014.

Liu, H. and Chandrasekar, V.: Classification of hydrometeor type based on multiparameter radar measurements: Development of a Fuzzy Logic and Neuro Fuzzy systems and in-situ verification, J. Atmos. Ocean. Tech., 17, 140-164, 2000.

Marshall, J. S. and Palmer, W. M.: The distribution of raindrops with size, J. Meteorol., 5, 165-166, 1948.

Marzano, F. S., Montopoli, M., Picciotti, E., and Vulpiani, G.: Inside volcanic clouds. Remote sensing of ash plumes using microwave weather radars, B. Am. Meteorol. Soc., 94, 1567-1586, 2013.

Mason, B. J.: The Physics of Clouds, Clarendon Press, Oxford, UK, 688 pp., 1971.

Matrosov, S. Y., Kingsmill, D. E., and Martner, B. E.: The utility of $\mathrm{X}$-band polarimetric radar for quantitative estimates of rainfall parameters, J. Hydrometeorol., 6, 248-262, 2005.

Matrosov, S. Y., Cifelli, R., and Gochis, D.: Measurements of heavy convective rainfall in the presence of hail in flood-prone areas using an X-band polarimetric radar, J. Appl. Meteorol. Clim., 52, 395-407, 2013.

Matrosov, S. Y., Kennedy, P. C., and Cifelli, R.: Experimentally based estimates of relations between $\mathrm{X}$-band radar signal atten- uation characteristics and differential phase in rain, J. Atmos. Oceanic Technol., 31, 2442-2450, 2014.

Peel, M. C., Finlayson, B. L., and McMahon, T. A.: Updated world map of the Köppen-Geiger climate classification, Hydrol. Earth Syst. Sci., 11, 1633-1644, doi:10.5194/hess-11-16332007, 2007.

Rasmussen, R. M. and Heymsfield, A. J.: Melting and shedding of graupel and hail, J. Atmos. Sci., 44, 2754-2763, 1987.

Rubel, F. and Kottek, M.: Observed and projected climate shifts 1901-2100 depicted by world maps of the KoppenGeiger climate classification, Meteorol. Z., 19, 135-141, doi:10.1127/0941-2948/2010/0430, 2010.

Ryzhkov, A. V., Kumjian, M. R., Ganson, S. M., and Khain, A. P.: Polarimetric radar characteristics of melting hail. Part I: Theoretical simulations using spectral microphysical modeling, J. Appl. Meteorol. Clim., 52, 2849-2870, 2013.

Schneebeli, M., Sakuragi, J., Biscaro, T., Angelis, C. F., Carvalho da Costa, I., Morales, C., Baldini, L., and Machado, L. A. T. Polarimetric X-band weather radar measurements in the tropics: radome and rain attenuation correction, Atmos. Meas. Tech., 5, 2183-2199, doi:10.5194/amt-5-2183-2012, 2012.

Seliga, T. A. and Bringi, V. N.: Potential use of radar reflectivity measurements at orthogonal polarizations for measuring precipitation, J. Appl. Meteorol., 15, 69-76, 1976.

Seliga, T. A., Aydin, K., Cato, C. P., and Bringi, V. N.: Use of the differential reflectivity radar technique for observing convective systems, in: Cloud Dynamics, edited by: Agee, M. and Asai, T., Reidel, Dordrecht, the Netherlands, 285-300, 1982.

Smyth, T. J., Blackman, T. M., and Illingworth, A. J.: Observations of oblate hail using dual polarization radar and implications for hail-detection schemes, Q. J. Roy. Meteor. Soc., 125, 993-1016, 1999.

Snyder, J. C., Bluestein, H. B., Zhang, G., and Frasier, S. J.: Attenuation correction and hydrometeor classification of highresolution, X-band, dual-polarized mobile radar measurements in severe convective storms, J. Atmos. Ocean. Tech., 27, 19792001, doi:10.1175/2010JTECHA1356.1, 2010.

Tabary, P., Vulpiani, G., Gourley, J. J., Illingworth, A. J., Thompson, R. J., and Bousquet, O.: Unusually high differential attenuation at C-band: Results from a two-year analysis of the French Trappes polarimetric radar data, J. Appl. Meteorol. Clim., 48, 2037-2053, 2009.

Testud, J., Bouar, E. L., Obligis, E., and Ali-Mehenni, M.: The rain profiling algorithm applied to polarimetric weather radar, J. Atmos. Ocean. Tech., 17, 332-356, 2000.

Vivekanandan, J., Yates, D. N., and Brandes, E. A.: The influence of terrain on rainfall estimation from reflectivity and specific propagation phase observations, J. Atmos. Ocean. Tech., 16, 837-845, 1999.

Vulpiani, G., Tabary, P., Parent du Chatelet, J., and Marzano, F. S.: Comparison of advanced radar polarimetric techniques for operational attenuation correction at C Band, J. Atmos. Ocean. Tech., 25, 1118-1135, 2008

Vulpiani, G. and Baldini, L.: Observations of a severe hailbearing storm by an operational X-band polarimetric radar in the Mediterranean area, in: Proceed. of the 36th AMS Conference on Radar Meteorology, 16-20 September 2013, Breckenridge, CO, USA, 2013. 
Vulpiani, G., Montopoli, M., Delli Passeri, L., Gioia, A., Giordano, P., and Marzano, F. S.: On the use of dual-polarized C-band radar for operational rainfall retrieval in mountainous areas, $\mathrm{J}$. Appl. Meteorol. Clim., 51, 405-425, 2012.

Waldvogel, A., Federer, B., and Grimm, P.: Criteria for the detection of hail cells, J. Appl. Meteorol., 18, 167-172, 1979.

Wang, Y. and Chandrasekar, V.: Quantitative precipitation estimation in the CASA X-band dual-polarization radar network, J. Atmos. Ocean. Tech., 27, 1665-1676, 2010.
Zrnić, D. S., Bringi, V. N., Balakrishnan, N., Aydin, K., Chandrasekar, V., and Hubbert, J.: Polarimetric measurements in a severe hailstorm, Mon. Weather Rev., 121, 2223-2238, 1993.

Zrnić, D. S., Raghavan, R., and Chandrasekar, V.: Observations of copolar correlation coefficient through a bright band at vertical incidence, J. Appl. Meteor., 33, 45-52, 1994.

Zrnić, D. S., Ryzhkov, A. V., Straka, J., Liu, Y., and Vivekanandan, J.: Testing a procedure for the automatic classification of hydrometeor types, J. Atmos. Ocean. Tech., 18, 892-913, 2001. 